\title{
Multi-surveyor detection-mark-redetection as a powerful tool for butterfly population monitoring in the pre-imaginal stage
}

\author{
Heiko Hinneberg ${ }^{1}$, Jörg Döring ${ }^{2}$, Gabriel Hermann $^{3}$, Gregor Markl ${ }^{4}$, Jennifer Theobald ${ }^{3}$, \\ Ines Aust ${ }^{5}$, Thomas Bamann ${ }^{5}$, Ralf Bertscheit ${ }^{2}$, Daniela Budach ${ }^{6}$, Jana Niedermayer ${ }^{7}$, \\ Alicia Rissi ${ }^{1}$, and Thomas Gottschalk ${ }^{1}$ \\ ${ }^{1}$ Rottenburg University of Applied Forest Sciences \\ ${ }^{2}$ private \\ ${ }^{3}$ Arbeitsgruppe für Tierökologie und Planung GmbH (Filderstadt) \\ ${ }^{4}$ University of Tubingen Faculty of Science \\ ${ }^{5}$ Regierungspräsidium Tübingen \\ ${ }^{6}$ ISTE Baden-Württemberg e. V. \\ ${ }^{7}$ Institut für Landschaftsökologie und Naturschutz (ILN) Bühl
}

January 5, 2022

\begin{abstract}
1. For many elusive insect species, which are difficult to cover by standard monitoring schemes, innovative monitoring methods are needed to gain robust data on population trends. We suggest a monitoring of overwintering larvae for the endangered nymphalid butterfly Limenitis reducta. 2. We tested one removal and three detection-mark-redetection (DMR) approaches in a field study in the "Alb-Donau" region, Germany. We replaced movement of the study organisms by random movement of multiple different surveyors, and we examined the model assumption of equal detectability using simulations. 3. Our results indicate that multi-surveyor removal/DMR techniques are suitable for estimating abundance of overwintering L. reducta larvae. Detection probabilities varied with surveyor experience and the uncertainty of population estimates increased with a decrease in personnel expenditure. Estimated larval densities on a spruce clear-cut ranged between one and three individuals per 100 $\mathrm{m}^{2}$. 4. We suggest a detection-mark-redetection (DMR) approach with three trained surveyors for the monitoring of L. reducta populations in the pre-imaginal stage. Besides L. reducta, the proposed method is likely to be suitable for other insect taxa with specific immobile life-stages and some sessile organisms, e.g. corals, elusive plants, or fungi.
\end{abstract}

\section{Hosted file}

MultiSurveyor_DMR_for PreImaginal_Butterflies.docx available at https://authorea.com/users/ 454150/articles/551862-multi-surveyor-detection-mark-redetection-as-a-powerful-tool-forbutterfly-population-monitoring-in-the-pre-imaginal-stage 